\title{
ATENDIMENTO EDUCACIONAL ESPECIALIZADO - AEE NA EDUCAÇÃO INFANTIL: ENTRAVES E POSSIBILIDADES.
}

\author{
ATENDIMENTO EDUCACIONAL ESPECIALIZADO NA EDUCACIÓN \\ INFANTIL: OBSTÁCULOS Y POSSIBILIDADES
}

\author{
SPECIALIZED EDUCATIONAL ASSISTANCE IN EARLY CHILDHOOD \\ EDUCATION: OBSTACLES AND POSSIBILITIES
}

Gabriela MACHADO ${ }^{1}$

Morgana de Fátima Agostini MARTINS ${ }^{2}$

RESUMO: O trabalho apresenta os resultados de uma pesquisa que buscou compreender o Atendimento Educacional Especializado na Educação Infantil em Dourados/MS. Caracterizada como um Estudo de Caso de cunho qualitativo, a coleta de dados contou com sessões de observação e aplicação de dois questionários diferentes. Utilizou-se ainda de um checklist para verificar quais os materiais disponíveis para o serviço e as anotações do caderno de campo que registrou as observações. Os resultados apontaram que falta adequação dos materiais oferecidos pelo MEC para o AEE da Educação infantil e a necessidade de mais professores especializados para realizar este atendimento. Concluímos que existe necessidade de maiores investimentos em recursos humanos, tanto para mais contratação quanto para formação.

PALAVRAS-CHAVE: Educação especial. Educação infantil. Formação de professores. Atendimento educacional especializado. Sala de recurso multifuncional.

RESUMEN: Este trabajo presenta los resultados de una investigación que buscó comprender la atención Educacional Especializada en la Educación Infantil en Dourados/MS. Caracterizada con un estudio de caso de cuño cualitativo, la recopilación de datos contó con sesiones de observación y aplicación de dos cuestionarios diferentes. También utilizo un checklist para verificar los materiales disponibles para el servicio y las anotaciones del cuaderno de campo que registro las observaciones. Los resultados apuntan que falta adecuación en los materiales ofrecidos por el Ministerio de Educación para el AEE de la Educación Infantil y la necesidad de más profesores especializados para efectuar esta atención. Concluimos que existe la necesidad de mayores inversiones em recursos humanos, tanto para la contratación y formación.

PALABRAS CLAVE: Educación especial. Educación infantil. Formación de professores. Atención educacional especializado. Classes de recursos multifuncionales.

${ }^{1}$ Universidade Federal da Grande Dourados (UFGD), Dourados - MS - Brasil. Doutoranda em Educação. ORCID: <https://orcid.org/0000-0002-7362-2332>.E-mail: gabrielamachado.psi@gmail.com

${ }^{2}$ Universidade Federal da Grande Dourados (UFGD), Dourados - MS - Brasil. Docente Permanente do Programa de Pós-graduação em Educação - PPGEdu. Professora Associada de Educação Especial da Faculdade de Educação. ORCID: <https://orcid.org/0000-0001-9117-1320>. E-mail: morganamartins@ufgd.edu.br

RIAEE - Revista Ibero-Americana de Estudos em Educação, Araraquara, v. 14, n. esp. 1, p. 746-759, abr., 2019. E-ISSN: 1982-5587. 
ABSTRACT: The article presents the results of a research aimed to understand Specialized Educational Assistance in multifunctional resource rooms, during Early Childhood, located in Dourados / MS. Characterized as a Qualitative Case Study, the data collection included sessions of observation and application of two different questionnaires. A checklist was also used to check what materials were available for the service and the annotations of the field book that recorded the observations. The results pointed out lack of adequacy in materials offered to Specialized Educational Assistance of Infant Education and the need for more specialized teachers to carry out this service. We conclude that there is a need for greater investments in human resources, both for hiring and training.

KEYWORDS: Special education. Infant education. Teacher training. Specialized educational assistance. Multifunctional resource room.

\section{Introdução}

A Educação Infantil, reconhecida como a primeira etapa da educação básica, tem assumido um papel cada vez mais relevante no processo educacional. Destacando as constantes discussões sobre a inclusão escolar iniciadas nos anos 1990, junto com o avanço das políticas públicas que têm tido como meta as pessoas com deficiência, a Educação Especial tem assumido um lugar de importância também nessa fase da escolarização.

Segundo Carneiro e Dall'Acqua (2014), a escola configurou-se, desde seu início, para atender a uma parcela privilegiada socialmente, considerada elegível, com boas condições econômicas. A perspectiva defendida a partir do discurso de inclusão escolar e de educação para todos requer que haja mudanças em toda estrutura da escola, "[...] pois a escola para todos tem que garantir entrada, permanência e qualidade, cumprindo efetivamente seu papel social” (CARNEIRO; DALL'ACQUA, 2014, p. 11). Esta concepção de escola para todos inclui reformulações nas instituições e na atuação dos professores, que deverão atender a todas as demandas, adaptando-se às particularidades de cada aluno.

Oliveira e Padilha (2013) consideram que a formação dos professores para atuar com crianças pequenas e que são consideradas Público-Alvo da Educação Especial (PAEE) tem sido um dos grandes desafios para a implementação de políticas para a inclusão escolar.

O atendimento oferecido a essa faixa etária na Educação Infantil parece permeado por práticas precárias, desencadeadas pela falta de formação e de conhecimento dos profissionais sobre as necessidades dos seus alunos e procedimentos pedagógicos que favoreçam o desenvolvimento infantil. A visão assistencialista da Educação Infantil ainda transpassa as ações docentes, mesmo que de forma velada. As crianças, nesta idade, passam por momentos 
importantes no desenvolvimento que podem ser potencializados com o planejamento de atividades didáticas que as preparem para as etapas seguintes na escolarização, numa perspectiva de inclusão escolar.

Em busca dessa proposta, o Atendimento Educacional Especializado (AEE) nos Centros de Educação Infantil Municipal - CEIM de Dourados teve início no ano de 2012. Segundo dados do Núcleo de Supervisão Técnica e Estatística, até julho de 2016 Dourados contava com 38 CEIM em funcionamento, e em três destes já estava implantada a Sala de Recurso Multifuncional (SRM). Há uma professora responsável pelo atendimento nessas salas dos 3 CEIM. O número de crianças matriculadas na faixa de zero a quatro anos nos CEIM era de 2.434 crianças. As crianças com idade a partir de cinco anos que são matriculadas nas préescolas somam o total de 3.508. O número de alunos PAEE indicados na Educação Infantil no ano de 2016 foi de 58 crianças, considerando CEIM e pré-escola, ou seja, crianças de zero a cinco anos e 11 meses.

Dados do censo escolar de 2015 mostram que o número de matrículas nos Centros de Educação Infantil Municipal tem aumentado no decorrer dos últimos anos. O número de crianças matriculadas em 2010 era de 1.456 crianças, já em 2015 esse número aumentou para 2.378 crianças. O número de crianças consideradas como público-alvo da Educação Especial também aumentou, foi de duas crianças matriculadas, em 2010, para 14 crianças em 2015 (BRASIL, 2015).

Nessa pesquisa o objetivo geral foi caracterizar e compreender o Atendimento Educacional Especializado ofertado nas salas de recursos multifuncionais dos Centros de Educação Infantil Municipal de Dourados/MS. Teve por objetivos específicos: a) Identificar o perfil profissional do professor responsável pelo AEE nas SRM da Educação Infantil; b) Conhecer e descrever a estrutura física, assim como os recursos materiais utilizados neste espaço; c) Conhecer e descrever as práticas pedagógicas realizadas pela professora especialista com as crianças no atendimento educacional especializado e d) Conhecer as versões do professor regente e do apoio educacional sobre o AEE.

\section{Metodologia}

Esta pesquisa foi baseada nas premissas da pesquisa qualitativa e será descrita como um estudo de caso (BOGDAN; BIKLEN 1994). Os participantes da pesquisa foram a professora responsável pelo AEE na SRM dos três Centros de Educação Infantil Municipal; 
quatro professoras regentes que atendiam às crianças matriculadas nas SRM; e uma estagiária responsável pelo apoio educacional que fazia o acompanhamento de uma das crianças.

O procedimento de coleta de dados foi conduzido em quatro etapas. A primeira etapa foi realizada em 2015 e consistiu em duas sessões de observações, com 2 horas cada, dos atendimentos realizados pela professora da SRM e pela caracterização do perfil das crianças por ela atendidas. Foi realizada no CEIM que possuía maior número de crianças identificadas e atendidas. Essa etapa foi interrompida por uma paralisação de professores, mas foi de fundamental importância para aprimorar os procedimentos metodológicos que foram aplicados no ano de 2016.

Para a segunda e terceira etapas, foram elaborados dois questionários, tendo como referência instrumentos já existentes (RODRIGUES, 2015; MILANESI, 2012). Para a quarta etapa foi construído um checklist de materiais. Os questionários abordaram questões referentes à formação acadêmica e profissional da professora da SRM, das professoras regentes e do profissional de apoio educacional (que é destinado a atender crianças PAEE nas salas regulares). Os instrumentos ainda buscaram levantar e caracterizar a estrutura física da escola, os materiais e recursos tecnológicos disponíveis; as características e especificidades (estratégias e recursos) do atendimento oferecido. Buscou construir o perfil das crianças atendidas, coletando dados como idade, diagnóstico médico, sexo e as principais características levantadas pelas professoras, bem como aspectos da relação entre o professor do AEE e o professor regente.

Já no ano de 2016, foi iniciada a etapa dois, com a aplicação do questionário com a professora da SRM. A terceira etapa consistiu em duas sessões de observação (duas horas cada) das SRM para identificação dos materiais disponíveis utilizando o checklist elaborado. Esse instrumento teve como base o documento do Ministério da Educação "Manual de orientação: Programa de implementação de sala de recursos" (BRASIL, 2010). Na quarta etapa, foi aplicado o questionário com as professoras regentes e com a profissional de apoio educacional que atendia aos alunos identificados como PAEE.

Para a análise dos resultados foi realizada a tabulação dos dados obtidos com os questionários e com as observações das SRM. Foram caracterizadas as profissionais em atuação, as crianças atendidas e os recursos materiais existentes. Estes dados possibilitaram análises que fomentaram a discussão sobre como tem sido oferecido o AEE na educação infantil, seus entraves e possibilidades. 


\section{Resultados e Discussão}

Os resultados e discussão serão apresentados em duas partes que consideramos como Entraves e Possibilidades para o Atendimento Educacional Especializado na Educação infantil.

Como entraves, elencamos os subtítulos a) atuação da professora da SRM; b) materiais disponíveis na SRM; c) transição do aluno PAEE para outra escola e d) como se operacionalizam o planejamento e a avaliação. Já como possibilidades foram elencados: a) relação da professora da SRM com a família; b) Ensino Colaborativo como alternativa de trabalho em equipe e c) como o laudo médico interfere no AEE na Educação Infantil.

\section{Entraves:}

a) Atuação da professora da SRM: Existem vários fatores que influenciam a atuação, como o fato de ela ter que se dividir entre quatro CEIM para realizar os atendimentos (três possuem SRM, e um de forma itinerante), a inadequação dos materiais oferecidos - que serão discutidos mais a frente - e também a sua formação. A mesma estava neste cargo e à frente dos atendimentos da SRM há mais de dois anos. Possuía mais de um curso de especialização, mas nenhum deles especificamente em Educação Infantil ou Educação Especial. Para Amorim (2015), a questão a ser discutida não é o professor não possuir formação adequada, afinal muitos deles passam por diversas formações e cursos durante a vida profissional, mas sim a adequação dos cursos. A partir do momento que os alunos PAEE passam a ter o direito garantido por lei de frequentarem a escola, e serem nela incluídos, respeitando os princípios da inclusão escolar, as Instituições de Ensino Superior e o governo (federal, estadual e municipal) tem o dever de oferecer formação adequada para todos os profissionais da escola.

Tratando-se de Educação Especial, essa necessidade de capacitação do professor se torna mais evidente, mas em todas as etapas da educação existem crianças que aprendem de formas diferentes e cabe ao professor identificar de que forma seu trabalho pode potencializar essa aprendizagem. (MACHADO, 2017, p. 78)

Concordando com a colocação de Amorim (2015), defende-se uma formação problematizadora, que prepare o profissional para refletir sobre as necessidades dos alunos e proporcionar meios para que o desenvolvimento ocorra. 
b) Materiais disponíveis na SRM: A maioria dos materiais não são utilizados pela professora, por serem incompatíveis com a faixa etária, sendo necessário que a professora confeccione os materiais para realização de suas atividades. A seguir, será apresentado o resultado do checklist. De acordo com a professora, as três SRM possuem os mesmos materiais.

Quadro 1 - Materiais disponibilizados pelo MEC para às SRM

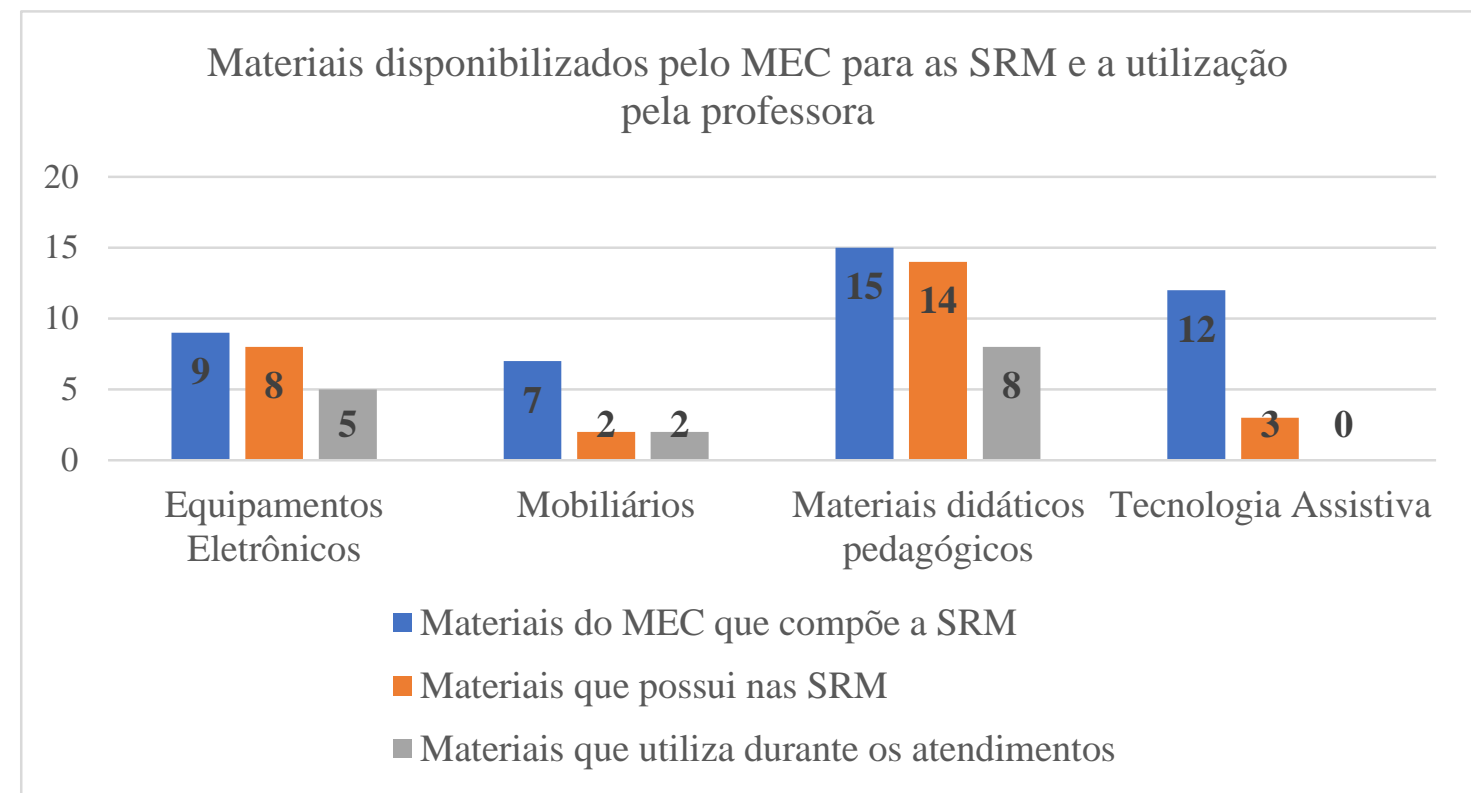

Fonte: Machado (2017, p. 62).

Ao analisar esses resultados, é evidente a necessidade de uma adequação do Ministério da Educação com relação aos materiais oferecidos para o AEE da Educação Infantil.

[...] dos 43 materiais da SRM descritos no checklist, a professora da SRM alegou possuir 27 itens, dos quais utiliza apenas 15. Destes 15 itens, apenas 08 são materiais didáticos pedagógicos, sendo dois utilizados de forma adaptada, ou seja, com outra função. Os 07 materiais restantes são computadores, impressora, roteador wireless e mobiliários. (MACHADO, 2017, p. 80).

A falta de materiais adequados, somado às lacunas na formação e falta de investimentos, torna o trabalho da professora ainda mais difícil. O suporte adequado é essencial para que o trabalho possa ocorrer de forma efetiva.

c) Transição do aluno PAEE para outra escola: Ao analisar a caracterização das crianças atendidas em 2015 e em 2016, foi possível observar que nenhuma das seis crianças atendidas em 2015 prosseguiram com os atendimentos no ano seguinte. De acordo com a 
professora, algumas crianças mudaram de CEIM, outras mudaram para outra escola por estar em idade para iniciar a pré-escola. Não houve acompanhamento para esta transição e nenhum diálogo entre as instituições.

Checconi (2016), em sua pesquisa sobre a transição da Educação Infantil para o Ensino Fundamental, destaca a importância de um diálogo institucional e pedagógico para que esta nova fase não cause impacto negativo na trajetória escolar. A autora não menciona os impactos para os alunos PAEE neste processo de transição, mas podemos inferir que, para este público, a troca de informações entre as instituições responsáveis se faz ainda mais importante, considerando que além da adaptação em sala de aula o trabalho realizado durante o AEE também deve ter continuidade.

d) Planejamento e Avaliação: Durante a coleta de dados, a professora do AEE disponibilizou uma pasta com informações dos alunos atendidos em 2015. Foi possível observar que tanto o plano de aula quinzenal, quanto as avaliações, que eram anotações sobre o desempenho da criança, eram feitas de forma incompleta, sem definição de objetivos e das metodologias utilizadas.

Com relação ao registro, planejamento e avaliação, em se tratando da Educação Infantil, Rodrigues (2015) afirma que quando a avaliação se pauta na observação e registro do desenvolvimento do aluno e no desempenho obtido por meio das atividades, auxiliam o professor a refletir sobre o processo de aprendizagem do aluno. Ainda afirma que o planejamento educacional especializado é importante para que possa evitar que as necessidades de cada aluno não sejam abordadas forma adequada. $\mathrm{O}$ planejamento auxilia para que as atividades alcancem os objetivos propostos para cada criança.

\section{Possibilidades}

a) Relação da professora da SRM com a família: O trabalho com pais, de acordo com Machado (2017, p.78), “[...] ainda é incipiente e não tem tomado forma nos espaços escolares, devido à falta de disponibilidade de tempo para o contato, o que faz com que não haja sistematização no trabalho com os familiares de forma regular e com objetivos claros". Nesta pesquisa, o contato com os pais era realizado de maneira informal, geralmente com conversas via aplicativo de mensagens no celular, onde professora e pais compartilhavam imagens da criança e informações. Está é uma alternativa, mas não deve ser a única forma de interlocução entre a família e a escola, especialmente tratando-se de crianças pequenas e 
PAEE. A aproximação dos pais com a professora é importante para bons resultados dos atendimentos. Como afirma Rodrigues (2015), a escola vê na família agentes que possuem objetivos diferentes. E, ainda que os pais considerem a importância da escolarização na vida de seus filhos, tem dificuldades em colaborar com a escola. Para os professores, a parceria com os pais no processo limita-se a reproduzir o que é feito na escola, e a escola não investe em indicações para que os pais possam se envolver com questões escolares de maneira mais efetiva. Escola e família são instituições que possuem suas diferenças, mas que podem - e devem - se complementar.

b) Ensino Colaborativo como alternativa: O Ensino Colaborativo, de acordo com Mendes, Vilaronga e Zerbato (2014), é uma prática importante para a promoção da inclusão escolar, pois, ao atender o aluno de forma individual na SRM, ratifica-se que o problema está apenas no aluno.

Quando o AEE é realizado na sala comum, onde o aluno passa a maior parte do seu tempo, os benefícios são maiores, pois envolve um maior número de pessoas nesse processo e os demais alunos podem desfrutar de estratégias e materiais diferenciados. Sobre isso, Carneiro (2012) afirma:

O trabalho de colaboração não se destina apenas a favorecer aos alunos com deficiência, mas beneficia a todos os alunos. Construir uma prática flexível capaz de atender as diferenças individuais e oportunizar outras formas de aprendizagem a todos os alunos promove um ambiente educacional democrático e justo, além de promover a prática reflexiva do professor, elemento indispensável para o novo paradigma que a educação inclusiva aponta. (CARNEIRO, 2012, p. 92)

Foi possível observar por parte da professora do AEE uma tentativa em realizar um trabalho colaborativo, porém, o excesso de trabalho e indisponibilidade de horários para realizar conversas mais aprofundadas impediram que pudesse ocorrer de forma efetiva, então sua atuação junto às demais professoras se pautava em conversas superficiais de trocas de informações.

c) Interferência do laudo médico no funcionamento do AEE na Educação Infantil: Muitas vezes, o laudo médico é utilizado como justificativa para não exigir algumas habilidades da criança, por previamente acreditar que ela não irá se desenvolver adequadamente. Por outro lado, o laudo médico pode auxiliar a professora no planejamento pedagógico, pois pode realizar pesquisas e entender melhor sobre aquela necessidade específica, e assim potencializar a capacidade da criança. Durante as observações, pôde ser 
verificado que mesmo quando o laudo médico ainda não existe ou quando o diagnóstico da criança "ainda não está fechado", a professora já iniciava seu trabalho de avaliação e intervenção. Numa perspectiva onde a intervenção precoce é a melhor produtora de prognósticos positivos, pareceu que não há engessamento e nem negligência por falta de rótulos. Ela começava a realizar tais atendimentos na sala regular, junto com os demais alunos, justificando ainda não ter uma vaga na SRM.

No município onde a pesquisa foi realizada há uma diretriz que permite essa proposta. A Nota Técnica $n^{\circ}$. 4/2014 afirma que o laudo não deve ser um critério para a realização do atendimento. Muitas vezes, a exigência desse documento diminui a demanda, que por ser apenas uma professora, seria impossível atender. Assim, o avanço se torna retrocesso: a não exigência do laudo avança na medida em que não discrimina e permite oportunidade, mas é retrocesso quando não há estrutura para a demanda. Mesmo assim, a preocupação em avaliar e intervir independente de fórmulas, pode ser uma possibilidade para o trabalho com crianças pequenas e em desenvolvimento.

Sobre o encaminhamento para realização do atendimento, de acordo com a investigação, alguns alunos já chegam com o laudo médico, mas, em geral, a avaliação inicial das crianças é realizada a partir da "suspeita" da professora regente. Em seguida, é um profissional (psicólogo) do núcleo de Educação Especial que efetiva essas avaliações. Não há um modelo de referência para a professora realizar suas avaliações. Nesse processo, sua opinião é a segunda opção.

O que percebemos é que o papel do profissional da Secretaria de Educação tem cumprido a função de "laudar" os identificados. A problemática que se apresenta é a valorização do saber clínico, baseado em questões orgânicas. Se essa prática se iniciasse com uma avaliação sistemática/formal da professora do AEE, veríamos uma prática muito mais voltada para a escola, com outros desdobramentos. Há que se pensar no empoderamento baseado em cooperação, formação e redes de apoio. Assim, parece que o AEE começará a se desprender do poder médico e não ficará mais refém de laudos que demoram a ser realizados, pela dificuldade da saúde pública que pouco tem favorecido a derivação de práticas pedagógicas inclusivas.

Apesar de o laudo médico não ser mais legalmente utilizado como critério de seleção para que possa receber o AEE, este ainda se faz presente no dia-a-dia de quem atua junto às crianças. Segundo Schmitz (2015), a forma como o professor interpreta o diagnóstico 
influencia a prática em sala de aula, considerando que ele vê a criança a partir de suas limitações e as relações são construídas a partir do fracasso da criança.

Com relação ao diagnóstico das crianças que recebem o AEE na Educação Infantil, foi notório o número de crianças com diagnóstico de autismo. Estudos realizados pelo grupo de pesquisas em Educação Especial, do qual esse trabalho faz parte, já tem mostrado o aumento no número de suspeitas e diagnósticos de TEA (FONTANA, 2013; SCHIMTZ, 2015; GARCIA, 2017).

Apesar de o diagnóstico realizado precocemente favorecer a criança, que passa a receber o tratamento adequado, este número é considerado muito alto, em se tratando da Educação Infantil, considerando o indicado por alguns autores (LAMPREIA; LIMA, 2011; SCHWARTZMAN, 2011) de que o ideal para o diagnóstico seria em torno dos três anos de idade.

\section{Considerações finais}

Este estudo buscou produzir conhecimento sobre como tem se operacionalizado o Atendimento Educacional Especializado nas Salas de Recurso Multifuncional presentes na Educação Infantil, ainda que diversas leis, decretos, portarias, diretrizes e outros documentos normativos postulam como este atendimento deva ocorrer de forma a auxiliar à prática docente.

Durante a realização de todo o trabalho, foi possível acompanhar e reconhecer o empenho da professora responsável pelo AEE em busca de que os atendimentos pudessem ocorrer de forma eficaz. Muitas vezes a professora utilizou de recursos próprios para a aquisição de materiais, para sua locomoção e até mesmo para a locomoção de alunos.

Pode-se observar que a prática do AEE destinado à Educação Infantil em Dourados tem sido basicamente voltada para o atendimento na (ou no interior da) SRM. O fato de este ser o principal modelo de atendimento isenta a escola como um todo da responsabilidade sobre este aluno. A escola permanece a mesma, como se o problema estivesse no aluno. Estes alunos passam a ser "reeducados" ou "apoiados", em um espaço específico, com um acompanhante específico, que de certa forma o protege e não o expõe aos seus pares e aos demais profissionais da escola.

Parece mais coerente com a perspectiva de inclusão escolar a ideia de que a professora especialista se dirija e atenda às crianças juntamente com a professora regente, no espaço da 
sala de aula comum, dividindo e ampliando saberes. Como nossa participante esboça, fazer até os entraves burocráticos.

A justificativa para este atendimento estar prioritariamente na SRM é a definição de um espaço com mobiliários e materiais didáticos específicos voltados a este público. Contudo, este argumento não se sustenta quando observamos que os recursos destinados a este espaço são pouco utilizados, pois ainda que estejam presentes e disponíveis, não são adequados e não atendem às demandas de crianças pequenas. Esta realidade nos faz indagar quais critérios são utilizados pelo Ministério da Educação para a seleção, compra e distribuição destes materiais destinados para a Educação Infantil.

Outro fator que parece contribuir para a manutenção desse modelo de AEE é a falta de investimento em concursos públicos para profissionais da área da Educação Especial, pois mantê-los junto aos professores regentes demandaria o vínculo de mais professores especialistas. Apesar da legislação brasileira indicar que o ingresso na profissão docente deve ser realizado, exclusivamente, por concurso, a realidade demonstra que há um grande contingente de professores contratados de forma temporária.

Será que os professores do AEE possuem autonomia sobre sua prática? As formações proporcionam aos professores uma visão crítica sobre sua atuação? Ao pensar na realidade vivida pela professora responsável pelo AEE em Dourados, podemos inferir que a autonomia não ocorre como deveria. O modelo de gestão do MEC confere uma autonomia irreal, pois, sem os investimentos adequados, o trabalho permanece limitado. O atual cenário do AEE na Educação Infantil exige que a organização se mantenha centralizada. Por mais coerente que seja, a postura flexível, descentralizada, que possibilitaria à professora do AEE percorrer os diferentes espaços da escola, propondo intervenções e redes de colaboração, depende de investimentos e de condições de trabalho diferentes das atuais.

Os investimentos aqui deveriam abranger inicialmente três áreas, para que pudéssemos avançar e promover melhorias no AEE realizado na Educação Infantil. O primeiro seria em infraestrutura, o que englobaria a implementação de mais Salas de Recursos Multifuncionais equipadas com recursos pedagógicos adequados para o público da Educação Infantil, considerando-se que este, embora não seja o mais indicado pelos estudiosos e pesquisadores do tema, é o modelo de política atualmente adotado pelo munícipio, que conta, contraditoriamente, com apenas três SRM para atender a 38 CEIM.

O segundo investimento necessário está nos recursos humanos. Durante toda a experiência nesse trabalho de campo foram relatadas as dificuldades encontradas para a 
realização do trabalho, por se tratar de apenas uma profissional especializada. Entre as dificuldades estão a falta de tempo para o contato com as professoras da sala comum e para a realização de atendimento de crianças que ainda não possuem laudo médico.

O terceiro investimento necessário é em uma formação voltada para a atuação em sala de aula com crianças pequenas, tanto para a professora especialista, quanto para os demais profissionais da escola. A dificuldade das professoras ao traçar objetivos durante as aulas e na realização das avaliações demonstra essa necessidade.

É importante ressaltar que quando chamamos a necessidade para a formação não estamos defendendo o modelo transmissivo que vem sendo, tradicionalmente, adotado pelas Secretarias de Educação. Esse modelo pauta-se em oficinas, reuniões, cursos de curta duração e outros recursos que suprimem a participação ativa dos docentes, que passam a ser meramente receptores dos conhecimentos produzidos por outros, desconsiderando-se o saber que vêm construindo em suas experiências vivenciadas em sala de aula ou SRM, os quais precisam vir à tona e serem socializados para que haja possibilidade de transformação em suas concepções. Quando não se oferece espaço para ouvir o que o profissional tem a dizer, corre-se o risco de que ele ouça, "aprenda", mas não modifique sua prática, pois internamente já possui um modelo no qual acredita e que não foi posto em conflito, tendo como parâmetro uma sólida teoria, para que pudesse ser transformado.

Nesta pesquisa, optou-se por analisar o funcionamento do AEE na SRM sob a ótica dos professores, mas seria importante que outros participantes que influenciam esse processo sejam ouvidos, como as famílias, os gestores públicos, os demais profissionais da escola e até mesmo os próprios alunos, o que lança a sugestão de que outros pesquisadores se ocupem dessa temática. Espera-se ter contribuído não apenas para a construção de melhorias nesse nível e modalidade de atendimento, mas para pensar quais caminhos a Educação Especial na Educação Infantil tem tomado, de forma que possamos romper com paradigmas em relação a estes espaços, buscando favorecer a inclusão escolar desde os primeiros passos.

\section{REFERÊNCIAS}

AMORIM, G. C. Organização e funcionamento do atendimento educacional especializado na educação infantil: estudo de caso. 2015. 139f. Dissertação (Mestrado em Educação) - Universidade Estadual Paulista “Júlio de Mesquita Filho”, Faculdade de Filosofia e Ciências, Marília, 2015. 
BOGDAN, R.; BIKLEN, S. K. Investigação qualitativa em educação: uma introdução à teoria e aos métodos. Porto: Porto Editora, 1994.

BRASIL. Manual de orientação: Programa de implantação de sala de recursos multifuncionais. Brasília: MEC/SEESP, 2010.

BRASIL. Ministério da Educação /Secretaria de Educação Especial. NOTA TÉCNICA NOTA TÉCNICA No 04 / 2014. Orientação quanto a documentos comprobatórios de alunos com deficiência, transtornos globais do desenvolvimento e altas habilidades/superdotação no Censo Escolar. Diário Oficial da União, Brasília, 2014.

BRASIL. Instituto de Estudos e Pesquisas Educacionais Anísio Teixeira. Ibge: cidades. 2015. Disponível em:

http://cidades.ibge.gov.br/xtras/temas.php?lang=\&codmun=500370\&idtema=156\&search=ma to-grosso-do-sul|dourados|ensino-matriculas-docentes-e-rede-escolar-2015. Acesso em: 24 mar. 2016.

CARNEIRO, R. U. C. Educação Inclusiva na educação infantil. Práxis educacional, Vitória da Conquista, v. 8, n. 12, p. 81-95, 2012.

CARNEIRO, R. U. C.; DALL'ACQUA, M. J. C. Inclusão Escolar na Educação Infantil. In: CARNEIRO, R. U. C.; DALL'ACQUA, M. J. C.; CARAMORI, P. M. (Org.) Educação Especial e Inclusiva: mudanças para escola e sociedade. Jundiaí, Paco Editorial, 2014. p. 1426.

CHECCONI, F. F. A Transição da Educação Infantil para o Ensino Fundamental: a criança no foco das investigações. 2016. 157f. Dissertação (Mestrado). Programa de PósGraduação em Processos de Ensino, Gestão e Inovação. Universidade de Araraquara, Araraquara, 2016.

LAMPREIA, C.; LIMA, M. M. R. Instrumento de Vigilância Precoce do Autismo: manual e vídeo. Rio de Janeiro, Edições Loyola, 2011.

MACHADO, G. Caracterização das práticas do Atendimento Educacional Especializado na Educação Infantil de Dourados/MS. 2017. 111f. Dissertação (Mestrado em Educação). Universidade Federal da Grande Dourados, Dourados, MS, 2017.

MENDES, E. G.; VILARONGA, C. A. R.; ZERBATO, A. P. Ensino Colaborativo como Apoio à Inclusão Escolar: unindo esforços entre educação comum e especial. São Carlos: EdUFSCar, 2014.

MILANESI, J. B. Organização e funcionamento das Salas de Recursos Multifuncionais em um município paulista. 2012. 185f. Dissertação (Mestrado em Educação). Universidade Federal de São Carlos, São Carlos, 2012.

OLIVEIRA, I. M.; PADILHA, A. M. L. Atendimento Educacional Especializado para crianças de zero a três anos. In: JESUS, D. M.; BAPTISTA, C. R.; CAIADO, K. R. M. (Orgs.) Prática Pedagógica na Educação Especial: multiplicidade do atendimento educacional especializado. Araraquara-SP: Junqueira \& Marin, 2013. p. 23-47. 
RODRIGUES, R. K. G. Atendimento Educacional Especializado na Educação Infantil: Interface com os pais e professores da classe comum. 2015. 156f. Dissertação (Mestrado em Educação). Universidade Federal de São Carlos, São Carlos, 2015.

SCHMITZ, A. O. Desenvolvimento de estratégias pedagógicas a partir da CARS Childhood Autism Rating Scale - versão em português, na inclusão escolar de crianças com TEA. 2015. 75f. Dissertação (Mestrado em Educação). Universidade Federal da Grande Dourados, Dourados, MS, 2015.

SCHWARTZMAN, J. S.; ARAÚJO, C. A de. Transtorno do espectro do autismo - TEA. São Paulo: Memnon, 2011.

\section{Como referenciar este artigo}

MACHADO, Gabriela.; MARTINS, Morgana de Fátima Agostini. Atendimento educacional especializado - AEE na Educação Infantil: entraves e possibilidades. Revista IberoAmericana de Estudos em Educação, Araraquara, v. 14, n. esp. 1, p. 746-759, abr., 2019. EISSN: 1982-5587. DOI: 10.21723/riaee.v14iesp.1.12204

Submetido em: 06/08/2018

Aprovado em: 21/09/2018 